\title{
Parental smoking and risk of childhood cancer: hospital-based case-control study in Shiraz
}

\author{
M. Edraki ${ }^{1}$ and M. Rambod ${ }^{7}$
}

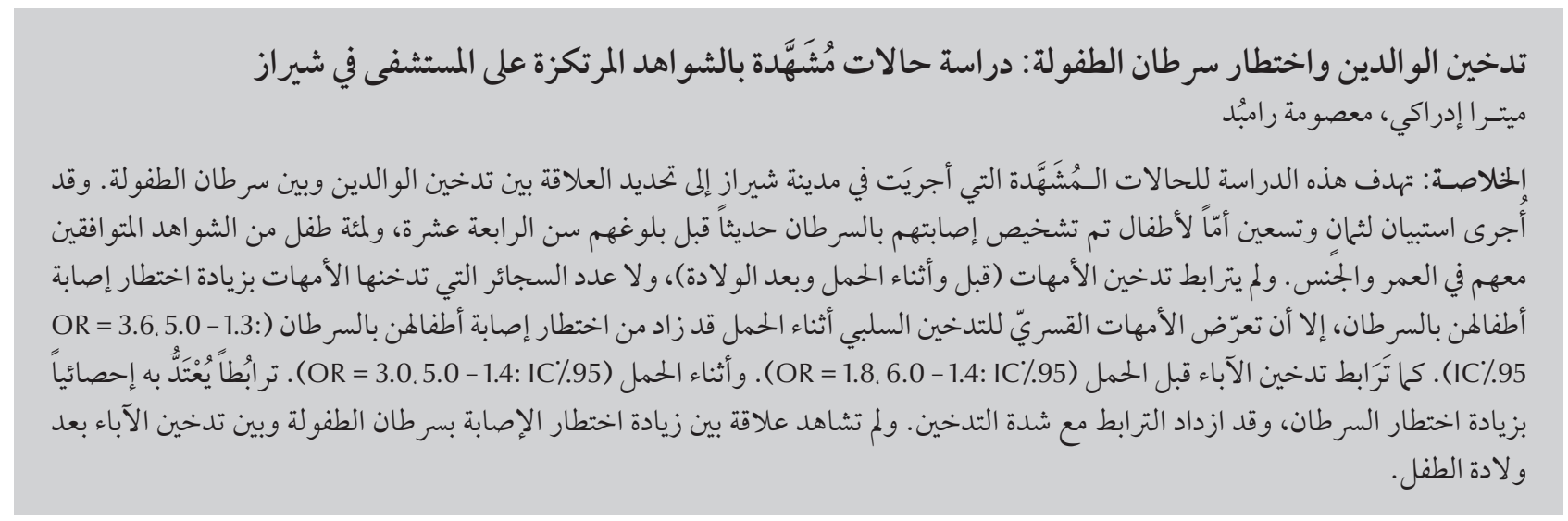

ABSTRACT This case-control study in Shiraz aimed to determine the relationship between parental smoking and childhood cancer. A questionnaire was completed by the mothers of 98 children newly diagnosed with cancer before the age of 14 years and 100 age- and sex-matched controls. Maternal smoking (prior to and during pregnancy and after the birth), and the numbers of maternal cigarettes smoked were not associated with an increased risk of childhood cancer. However, maternal exposure to passive smoke during pregnancy increased the risk of cancer childhood $(\mathrm{OR}=3.6,95 \% \mathrm{Cl}$ : 1.3-5.0). Father's smoking prior to $(\mathrm{OR}=1.8,95 \% \mathrm{Cl}: 1.4-6.0)$ and during pregnancy $(\mathrm{OR}=3.0,95 \% \mathrm{Cl}: 1.4-5.0)$ was significantly associated with an increased risk of cancer and this increased with heavy smoking. There were no relationship between an enhanced risk of childhood cancer and father's smoking after the child's birth.

Tabagisme des parents et risque de cancer chez l'enfant : une étude cas-témoins en milieu hospitalier à Chiraz

RÉSUMÉ La présente étude cas-témoins, conduite à Chiraz, visait à déterminer la relation entre le tabagisme parental et le cancer chez l'enfant. Un questionnaire a été rempli par les mères de 98 enfants chez lesquels un diagnostic de cancer avait été posé récemment et avant l'âge de 14 ans et par 100 témoins appariés selon l'âge et le sexe. Le tabagisme maternel (avant, pendant et après la grossesse), et le nombre de cigarettes fumées par la mère n'étaient pas associés à un risque accru de cancer chez l'enfant. Toutefois, l'exposition de la mère au tabagisme passif pendant la grossesse augmentait le risque de cancer chez l'enfant (O.R. =3,6; IC à 95 \% :1,3-5,0). Le tabagisme paternel avant la grossesse de la mère (O.R. = 1,8; IC à $95 \%: 1,4-6,0)$ et pendant $(O . R .=3,0$; IC à $95 \%: 1,4-5,0$ ) était significativement associé à un risque accru de cancer, et ce risque était même supérieur en présence d'un tabagisme paternel important. Aucun lien n'a été retrouvé entre un risque accru de cancer chez l'enfant et le tabagisme paternel après la naissance.

${ }^{1}$ Department of Paediatric Nursing, Nursing and Midwifery, Shiraz University of Medical Science, Shiraz, Islamic Republic of Iran (Correspondence to M. Edraki: mitraedraki@yahoo.com).

Received: 07/07/09; accepted: 05/10/09 


\section{Introduction}

The evidence for a link between parental smoking during pregnancy and childhood cancer is controversial. Several types of childhood cancer have been researched in relation to parental smoking including kidney cancer, eye tumours, Ewing's sarcoma, lung cancer and endocrine tumours. However, the results are too varied to permit a conclusion [1].

Genetic changes that occur in certain childhood haematopoietic cancers may originate in utero [2]. A casecontrol study reported a non-significant increasing trend for risk of childhood leukaemia associated with paternal preconception smoking and a significantly decreasing trend for maternal smoking during pregnancy [3]. In contrast, a large case-control study did not detect evidence of the relationship between childhood leukaemia and paternal or maternal smoking before or during pregnancy [4]. Smoking also appears to lead to oxidative damage and aneuploidy of the sperm [5], supporting a finding that the rate of childhood cancer is higher in those whose fathers smoke more than 10 cigarettes per day [6]. Some studies $[7,8]$ but not others $[9,10]$ have shown a positive association between paternal smoking and brain tumours in children. A research study also indicated that regular exposure of the mother to the father's cigarette smoke during pregnancy was associated with an increased risk of astroglial tumours in the children [11]. Preston-Martin also reported a positive association between brain tumours and the mother living with a smoker during pregnancy [12].

Although the data are inconclusive at present, smoking remains an exposure of interest because of its known carcinogenicity for numerous organs [13]. The present study in Shiraz, Islamic Republic of Iran, aimed to add to the evidence on this subject with an analysis of paternal and maternal smoking during pregnancy and after the birth with the risk of childhood cancer.

\section{Methods}

Data were obtained from a hospitalbased case-control study conducted in Shiraz University of Medical Science (SUMS) between December 2007 and November 2008.

\section{Sample}

Eligible cases were all the children newly diagnosed with any type of cancer before the age of 14 years, whom the interviewers were authorized to contact by the physician. The inclusion criteria were having literate parents, no previous diagnosis of cancer and being diagnosed for at least 30 days (or since date of recurrence/relapse).

The sample size of the study with a power of $80 \%, \alpha=5 \%$, prevalence of cancer in children $=12.9 \%$ and odds ratios of 2.8 was estimated to be 120 persons in the case and control groups. A total of 220 childhood cancerpatients were newly diagnosed at the cancer centre of SUMS over the study period. Of these, 98 parents were eligible and participated in the study. The control subjects comprised 120 children without any disease or other birth defects who were selected randomly from the students in schools and day care in the 4 districts of the Ministry of Education, matched for age and sex. From the control group, 120 children/parents met the inclusion criteria and 100 of the parents consented to participate in the study and returned the questionnaire to the researcher. Therefore the final sample included 198 children and their parents.

\section{Data collection}

Medical interviewers conducted faceto-face interviews with the parents, using a specially designed questionnaire based on previous research $[14,18]$. This included questions on the parents' sociodemographic characteristics and the child's age and sex. Maternal smoking history included smoking status (ever smoked or current smoker: yes or no), intensity of smoking (number of cigarettes smoked per day) and the timing of smoking (before the current pregnancy, during the pregnancy and after the birth). The history of paternal smoking included the same questions as for maternal smoking. The mothers were asked whether during pregnancy the atmosphere at home was smoky (maternal exposure to passive smoke during pregnancy).

The study protocol was reviewed and approved by the ethics committee of the cancer research centre of SUMS. The parents were informed about the study, both verbally and in writing. Participation was voluntary and the parents could stop their involvement without giving any reason. The questionnaires were coded in order to guarantee anonymity.

The internal consistency of the questionnaire was measured using Cronbach alpha reliability $(\alpha=0.84)$. Content validity for the questionnaire was also supported.

\section{Analysis}

Descriptive statistics were used to examine the data. The non-parametric chisquared test and 2 independent samples $t$-test was used to assess the relationship between the variables. Statistical analysis was performed using unconditional logistic regression models including the stratification variables (age, sex and parental education) for measuring the risk of childhood cancer associated with parental smoking.

Separate analyses and regressions were also used to estimate specific odds ratios (ORs) and their 95\% confidence intervals (CIs) for cancer patients. SPSS, version 10.0 was used to create descriptive statistics, including frequency statistics and measures of central tendency, to describe the demographic characteristics of the sample and the major variables of the study. A $P$-value $\leq 0.05$ was considered statistically significant. 


\section{Results}

\section{Socioeconomic data}

The distribution of cases and controls by socioeconomic variables is shown in Table 1. There were slightly more males (51.0\%) than females with childhood cancer (49.0\%). However, a significantly higher percentage of children in the control group were female $\left(52.0 \%\right.$ versus $\left.48.0 \% ; \chi^{2}=0.26, P>0.05\right)$. The age distribution peaked in the case and control groups at ages $6-10$ years (58.2\% and $56.0 \%$ ). The groups were nearly identical in age: mean 8.9 (SD 4.4) years versus 8.9 (SD 4.4) years for the case and control groups respectively $(t=0.18, P>0.05)$. There were no statistically significant differences in the age and sex distributions between the case and control groups.

The mothers of the control group were significantly younger than those of the cases: mean age 32.2 (SD 5.4) years versus 35.3 (SD 6.9) years respectively $(t=5.18, P \leq 0.05)$. The father's age were also significantly different in the case and control groups: mean age 40.9 (SD 9.1) years versus 38.8 (SD 6.9) years respectively $(t=4.69, P \leq 0.05)$.

The case families were of significantly lower economic status than those of the controls $\left(\chi^{2}=7.13, P \leq 0.05\right)$. In addition, the level of education of the case families was significantly lower than the control group (for mother's education $\chi^{2}=87.43, P<0.001$; for father's education $\left.\chi^{2}=58.68, P<0.001\right)$.

\section{Smoking exposure and risk of cancer}

Among the mothers of cases, 1 $(1.0 \%)$ reported ever having smoked both prior to and during pregnancy, compared with 3 (3.0\%) of the control mothers. After the birth, the proportions of case and control mothers who had smoked were the same (1.0\%). The overall risk of cancer was not significantly associated with maternal smoking at any stage, prior to pregnancy $\left(\chi^{2}=0.64\right.$, $P>0.05)(\mathrm{OR}=0.33 ; 95 \%$ CI: $0.4-3.9)$, during pregnancy $\left(\chi^{2}=0.64, P>0.05\right)$ $(\mathrm{OR}=0.33$; 95\% CI: 0.4-3.0) or after the birth $\left(\chi^{2}=0.11, P>0.05\right)(\mathrm{OR}=.02$; 95\%, CI: 0.6-2.5) (Table 2).

The mothers in the case and control groups did not vary by the number of cigarettes smoked daily $(t=0.03$, $P>0.05$ ). Only 1 of the case mothers and 3 of the control mothers reported having smoked $\geq 5$ cigarettes during pregnancy. Thus there was no association with the number of cigarettes smoked by mothers ( $\mathrm{OR}=0.03,95 \%$ CI: $0.3-2.5$ ).

In the case group, $36.7 \%$ of fathers reported smoking prior to the mother's pregnancy compared with $29.0 \%$ of the control group fathers. Paternal smoking was associated with cancer prior to $\left(\chi^{2}\right.$ $=3.25, P<0.05)(\mathrm{OR}=1.8,95 \% \mathrm{CI}$ : 1.4-6.0) and during the mother's pregnancy $\left(\chi^{2}=3.18, P<0.05\right)(\mathrm{OR}=3.0$, 95\% CI: 1.4-5.0). In addition, there was an association between number of cigarettes smoked by fathers and childhood cancer $(t=2.58, P<0.05)$; children whose fathers smoked $\geq 11$ cigarettes per day during the mother's pregnancy had a $>2.7$-fold higher risk of cancer $(\mathrm{OR}=2.7,95 \%$ CI: 1.4-6.0). However, the relationship between childhood cancer and paternal smoking after the birth was not significant $(\mathrm{OR}=0.02$, 95\% CI: 0.3-5.9).

The regression analysis also showed a 3.6-fold increased risk of childhood cancer for mothers who reported being exposed to passive smoke during pregnancy $\left(\chi^{2}=4.23, P<0.05 ; \mathrm{OR}=3.6\right.$, 95\% CI: $1.3-5.0)$.

\section{Discussion}

This study found no relationship between the risk of cancer childhood and maternal cigarette smoking at any stage - prior to pregnancy, during pregnancy or after the birth. There are currently no arguments in support of an influence of maternal smoking during pregnancy on the risk of childhood cancer [14], tumours of the brain or central nervous system [15] and leukaemia $[3,14]$, and the present results are consistent with this fact. In only a few studies was maternal smoking significantly associated with the risk of cancer $[7,8,16]$. All the smoker mothers in the study smoked only 5 or less cigarettes per day. The low number of cigarettes smoked per day by mothers may partially explain the lack of association between maternal smoking and the risk of childhood cancer in our study. Our findings agree with those of case-control studies conducted in Germany and the UK $[3,17]$. In addition, MacArthur et al. reported there was no relationship between childhood cancer and number of cigarettes smoked during pregnancy [18].

On the other hand, the data showed an association between childhood cancer and father's smoking prior to and during pregnancy. There was also a 2.7-fold higher risk of cancer in children whose fathers smoked more than 11 cigarettes per day compared with men who did not smoke. This was similar to the results of Memegaux et al. [14].

Fraga et al. reported that the level of 8-hydroxy-2'-deoxyguanosine, a product of oxidative DNA damage, was $50 \%$ higher in the sperm of smokers compared with that of non-smokers [19]. Shi et al. demonstrated that, compared with non-smoking men, light and heavy smoking men were more likely to manufacture abnormal sperm with disomy of chromosome 15 , which could be linked to development of childhood cancer [20]. These data are consistent with a possible mechanism linking paternal preconception smoking to an enhanced risk of childhood cancer [21]. In a number of studies, paternal smoking, especially in the prenatal period, has been shown to increase the risk of childhood leukaemia [6-8,21-23]. In another study the associations with father's smoking in the absence of mother's smoking were found for all cancers combined, as well as for acute 


\begin{tabular}{|c|c|c|c|c|c|}
\hline \multirow[t]{2}{*}{ Variable } & \multicolumn{2}{|c|}{$\begin{array}{c}\text { Cases } \\
(n=98)\end{array}$} & \multicolumn{2}{|c|}{$\begin{array}{l}\text { Controls } \\
(n=100)\end{array}$} & \multirow[t]{2}{*}{ Statistics } \\
\hline & No. & $\%$ & No. & $\%$ & \\
\hline \multicolumn{6}{|l|}{ Child's age (years) } \\
\hline$<2$ & 3 & 3.1 & 3 & 3.0 & \\
\hline $2-5.9$ & 13 & 13.3 & 14 & 14.0 & \\
\hline $6-9.9$ & 58 & 58.2 & 56 & 56.0 & \\
\hline $10-14$ & 24 & 24.5 & 27 & 27.0 & $t=0.18$ \\
\hline Mean (SD) & \multicolumn{2}{|c|}{$8.87(4.42)$} & \multicolumn{2}{|c|}{$8.93(4.40)$} & $P>0.05$ \\
\hline \multicolumn{6}{|l|}{ Child's sex } \\
\hline Female & 48 & 49.0 & 52 & 52.0 & $\chi^{2}=0.26$ \\
\hline Male & 50 & 51.0 & 48 & 48.0 & $P>0.05$ \\
\hline \multicolumn{6}{|c|}{ Mother's age (years) } \\
\hline$<20$ & 3 & 3.1 & 4 & 4.0 & \\
\hline $20-24.9$ & 10 & 10.2 & 13 & 13.0 & \\
\hline 25-29.9 & 24 & 24.5 & 31 & 31.0 & \\
\hline $30-34.9$ & 38 & 38.8 & 42 & 42.0 & \\
\hline$\geq 35$ & 23 & 23.5 & 10 & 10.0 & $t=5.18$ \\
\hline Mean (SD) & \multicolumn{2}{|c|}{$35.25(6.87)$} & \multicolumn{2}{|c|}{$32.24(5.40)$} & $P \leq 0.05$ \\
\hline \multicolumn{6}{|l|}{ Father's age (years) } \\
\hline$<20$ & 0 & 0.0 & 0 & 0.0 & \\
\hline $20-24.9$ & 1 & 1.0 & 2 & 2.0 & $t=4.69$ \\
\hline $25-29.9$ & 26 & 26.5 & 29 & 29.0 & $P \leq 0.05$ \\
\hline $30-34.9$ & 29 & 29.6 & 32 & 32.0 & \\
\hline$\geq 35$ & 42 & 42.9 & 37 & 37.0 & \\
\hline Mean (SD) & \multicolumn{2}{|c|}{$40.92(9.12)$} & \multicolumn{2}{|c|}{$38.81(6.94)$} & \\
\hline \multicolumn{6}{|l|}{ Mother's education } \\
\hline Uneducated & 37 & 37.8 & 2 & 2.0 & \\
\hline 1-8 grade & 43 & 43.9 & 28 & 28.0 & $\chi^{2}=78.43$ \\
\hline $9-12$ grade & 14 & 14.3 & 31 & 31.0 & $P<0.001$ \\
\hline College degree & 4 & 4.1 & 39 & 39.0 & \\
\hline \multicolumn{6}{|l|}{ Father's education } \\
\hline Uneducated & 27 & 27.6 & 2 & 2.0 & \\
\hline 1-8 grade & 40 & 40.8 & 26 & 26.0 & $\chi^{2}=58.68$ \\
\hline 9-12 grade & 20 & 20.4 & 31 & 31.0 & $P<0.001$ \\
\hline College degree & 11 & 11.2 & 42 & 42.0 & \\
\hline \multicolumn{6}{|l|}{ Economic status } \\
\hline Good & 11 & 11.2 & 20 & 20.0 & \\
\hline Moderate & 58 & 59.2 & 73 & 73.0 & $\chi^{2}=7.13$ \\
\hline Poor & 29 & 29.6 & 7 & 7.0 & $P<0.05$ \\
\hline
\end{tabular}

$S D=$ standard deviation .

lymphocytic leukaemia, lymphomas and brain cancer [7].

The findings of the study indicated that there was no relationship between childhood cancer and paternal cigarette smoking after the birth. This result was similar to that of other studies $[14,22]$. However, Lee et al. reported that postnatal paternal smoking might play a role in the development of childhood leukaemia and that paternal smoking at home, rather than paternal smoking itself, significantly increased the risk of childhood leukaemia [22].

In the current study mother's exposure to smoke during pregnancy was associated with a significant increase in the risk of childhood cancer $(\mathrm{OR}=3.6,95 \%$ 


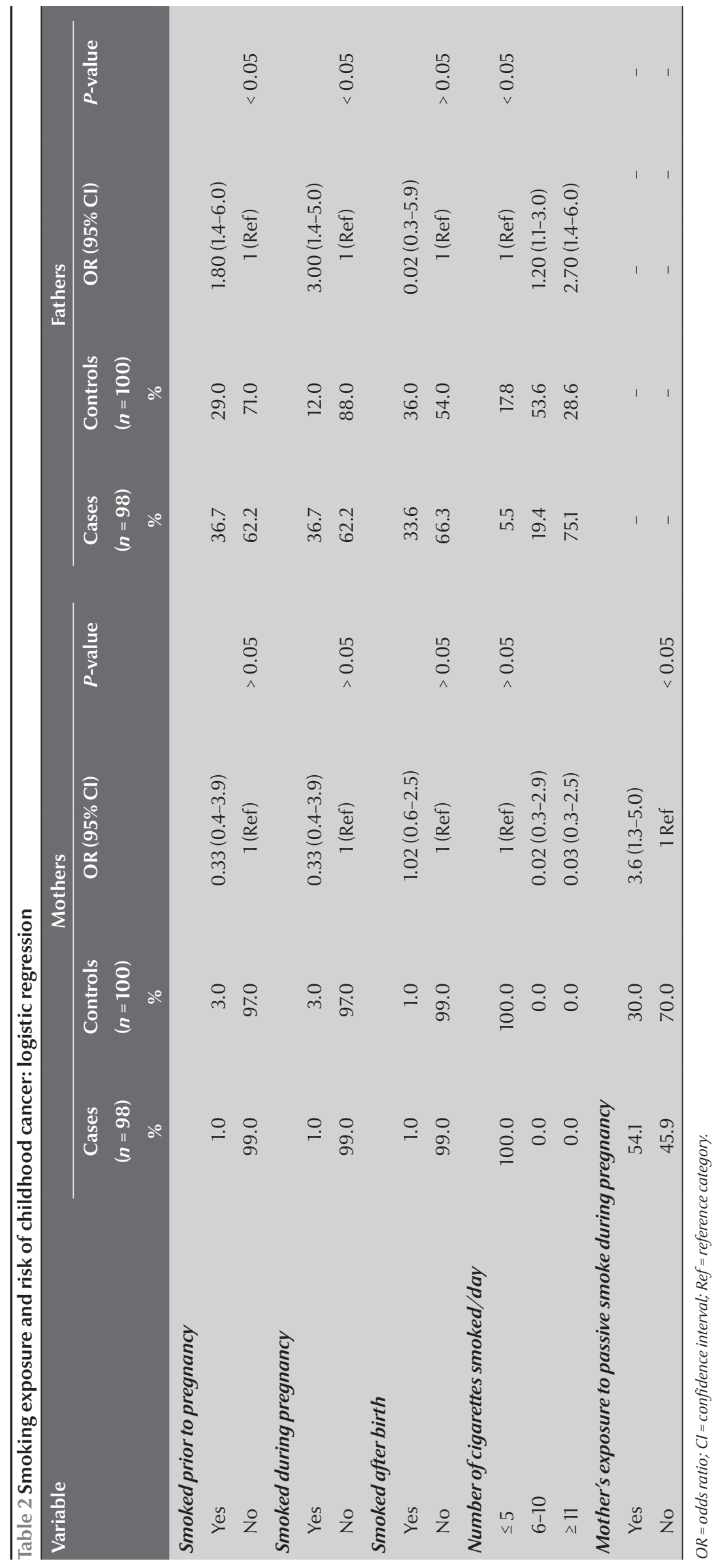

CI: 1.3-5.0). Maternal exposure to passive smoke during pregnancy has been associated with cancer in children [11]. However, other researchers indicated no association between cancers such as leukaemia and passive smoking at home [14]. Environmental exposure to cigarette smoking among children has been related to the level of biomarkers of genetic damage, such as an increased rate of sister chromatid exchange, a cytogenetic biomarker [24].

One limitation of the present study was the small number of cases with cancer, which led to high statistical uncertainty in the estimated associations.

There were also other important limitations in the study design. The children included in the study were aged from $0-14$ years. Therefore, especially for the older age groups of children with cancer, mothers and fathers were asked to remember specific details of smoking habits from a long time ago and this may have affected the accuracy of their recall. Furthermore, the lifetime duration of exposure to tobacco smoke was much longer for some children than others and this may also have affected their risk of developing cancer.

\section{Conclusion}

The results from the current study suggest that the paternal smoking and maternal exposure to passive smoke during pregnancy may be important in the development of childhood cancer.

Currently, the public is becoming generally more aware of the detrimental impact of passive maternal smoking during pregnancy on the health of the fetus. Parents need more information on the adverse effects of environmental tobacco smoke and the benefits of stopping smoking. The knowledge of a potentially harmful effect of paternal smoking exposure may give parents a strong incentive to quit smoking. 


\section{References}

1. Boffetta P, Trédaniel J, Greco A. Risk of childhood cancer and adult lung cancer after childhood exposure to passive smoke: A meta-analysis. Environmental Health Perspectives, 2000, 108:73-82.

2. Anderson LM. Environmental genotoxicants/carcinogens and childhood cancer: bridgeable gaps in scientific knowledge. Mutation Research, 2006, 608:136-156.

3. Pang D, McNally R, Birch JM. Parental smoking and childhood cancer: results from the United Kingdom Childhood Cancer Study. British Journal of Cancer, 2003, 88:373-381.

4. Brondum J et al. Parental cigarette smoking and the risk of acute leukemia in children. Cancer, 1999, 85:1380-1388.

5. Shi $Q$ et al. Cigarette smoking and aneuploidy in human sperm. Molecular Reproduction and Development, 2001, 59:417-421.

6. Chang JS et al. Parental smoking and the risk of childhood leukemia. American Journal of Epidemiology, 2006, 163:10911100

7. John EM, Savitz DA, Sandler DP. Prenatal exposure to parents smoking and childhood cancer. American Journal of Epidemiology, 1991, 133:123-132.

8. Sorahan T et al. Childhood cancer and parental use of tobacco: deaths from 1971 to 1976. British Journal of Cancer, 1997, 76:1525-1531.

9. Howe GR et al. An exploratory case-control study of brain tumors in children. Cancer Research, 1989, 49:4349-4352.

10. Kuijten RR et al. Gestational and familial risk factors for childhood astrocytoma: results of a case-control study. Cancer Research, 1990, 50:2608-2612.

11. Filippini $\mathrm{G}$ et al. Relation of childhood brain tumors to exposure of parents and children to tobacco smoke: the SEARCH international case-control study. Surveillance of Environmental Aspects Related to Cancer in Human. International Journal of Cancer, 2002, 100:206-213.

12. Preston-Martin S et al. N-nitroso compounds and childhood brain tumors: a case-control study. Cancer Research, 1982, 42:5240-5245.

13. Tobacco smoking. Summary of data reported and evaluation.. Tobacco Smoking, IARC. IARC Monographs on the Evaluation of the Carcinogenic Risk of Chemicals to Humans. Volume 38. Lyon,
World Health Organization/International Agency for Research on Cancer, 1986.

14. Menegaux F et al. Maternal coffee and alcohol consumption during pregnancy, parental smoking and risk of childhood acute leukaemia. Cancer Detection and Prevention, 2005, 29:487-493.

15. Polanska K et al. Environmental tobacco smoke exposure and children's health. Acta Paediatrica Supplement, 2006, 95:86-92.

16. Stjernfeldt $M$ et al. Maternal smoking during pregnancy and risk of childhood cancer. Lancet, 1986, 1:1350-1352.

17. Schüz J et al. Association of childhood cancer with factors related to pregnancy and birth. International Journal of Epidemiology, 1999, 28:631-639.

18. MacArthur AC et al. Risk of childhood leukemia associated with parental smoking and alcohol consumption prior to conception and during pregnancy: the cross-Canada childhood leukemia study. Cancer Causes and Control, 2008, 19:283-295.

19. Fraga CG et al. Smoking and low antioxidant levels increase oxidative damage to sperm DNA. Mutation Research, 1996, 351:199-203.

20. Greaves MF, Wiemels J. Origins of chromosome translocations in childhood leukaemia. Nature Reviews. Cancer, 2003, 3:639-649.

21. Sorahan T et al. Childhood cancer and parental use of tobacco: findings from the inter-regional epidemiological study of childhood cancer (IRESCC). British Journal of Cancer, 2001, 84:141-146.

22. Lee KM et al. Paternal smoking, genetic polymorphisms in CYP1A1 and childhood leukemia risk. Leukemia Research, 2009, 33:250-258.

23. Ji BT et al. Paternal cigarette smoking and the risk of childhood cancer among offspring of nonsmoking mothers. Journal of the National Cancer Institute, 1997, 89:238-244.

24. Mollerup $S$ et al. Sex differences in risk of lung cancer: Expression of genes in the $\mathrm{PAH}$ bioactivation pathway in relation to smoking and bulky DNA adducts. International Journal of Cancer, 2006, 119:741-744. 